\title{
Photocatalytic Degradation of a Textile Dye under UV and Solar Light Irradiation Using $\mathrm{TiO}_{2}$ and $\mathrm{ZnO}$ nanoparticles
}

\author{
Ouarda Brahmia ${ }^{1}$
}

\begin{abstract}
Dyes wastewaters from textile industries were reported to be major river contaminants. The commercial available $\mathrm{TiO} 2$ Degussa $\mathrm{P} 25$ and $\mathrm{ZnO}$ photocatalysts can be promising candidates for Methylene blue (MB) dye photocatalytic degradation under UV and solar light (SL) irradiation. Results showed a complete MB oxidation under UV irradiation due particularly to the high oxidation potential of the hydroxyl radical generated from irradiated semiconductors photocatalysts. $\mathrm{ZnO}$ exhibits a better photocatalytic activity as compared with $\mathrm{TiO} 2$ and the oxidation follows a pseudofirst- order kinetic with the two semiconductors. Under solar irradiation, MB oxidation was more efficient and faster than under UV light and $\mathrm{ZnO}$ showed almost similar photocatalytic degradation as compared with $\mathrm{TiO} 2$. The photocatalytic efficiency of all the processes used follows the following order: $\mathrm{ZnO} / \mathrm{SL} \geq \mathrm{TiO} 2 / \mathrm{SL}>$ $\mathrm{ZnO} / \mathrm{UV}>\mathrm{TiO} / \mathrm{UV}$. ZnO photocatalyst under solar light leads to achieve MB highest degradation efficiency.
\end{abstract}

Keywords - methylene Blue, photocatalysis, UV irradiation, solar light, $\mathrm{TiO} 2, \mathrm{ZnO}$.

\section{INTRODUCTION}

With development of textile industry, considerable attention was focused on the contamination of the environment caused by dyes pollutants. The removal of these hazardous chemicals from industrial wastewaters is one of the most important subject in pollution control due to their toxicities and slow biodegradation [1,2]. Photocatalytic oxidation is a highly effective process for the degradation of a wide range of pollutants [1,2]. This process occurs as a result of the interaction of a photocatalyst and UV radiation that yields highly reactive hydroxyl radicals, which are believed to be the main species responsible for the oxidation of organic compound $[3,4]$. The photocatalytic reaction proceeds on the surface of the semiconductors via several steps and the photocatalysis mechanism was described by many researchers [5]. Titanium dioxide $\mathrm{TiO} 2$ and zinc oxide $\mathrm{ZnO}$ are considered as good photocatalysts for removal of many organic compounds due to their chemical stability, high oxidation efficiency, cheap and environmentally friendly [6]. Sunlight is an abundantly available natural source of energy

\footnotetext{
${ }^{1}$ Laboratoire des Techniques Innovantes de Préservation de l'Environnement,

University of Mentouri Brothers, Constantine 1, Algeria..
}

that can be exploited for irradiation of semiconductors in the photodegradation of pollutants and make the process economically viable [6]. In this work, $\mathrm{TiO}_{2}$ and $\mathrm{ZnO}$ were used as photocatalysts for the detoxification of methylene blue (MB) dye that contaminates the surface and even the groundwater by photocatalysis under UV and direct solar radiation.

\section{EXPERIMENTAL}

\section{A. Materials}

Methylene blue was purchased from Aldrich, TiO2 Degussa P25 from Interchim (France) and $\mathrm{ZnO}$ from BioChem Pharma.

\section{B. Photocatalytic Procedure}

Experiments were carried out in a cylindrical quartz reactor of $100 \mathrm{ml}$. MB solution at initial $\mathrm{pH}$ mixed with $\mathrm{TiO}_{2}$ $(1 \mathrm{~g} / \mathrm{l})$ or $\mathrm{ZnO}(1 \mathrm{~g} / \mathrm{l})$ was first stirred for 30 minutes in obscurity to reach the adsorption-desorption equilibrium (16\% of $\mathrm{MB}$ were adsorbed on the surface of $\mathrm{TiO}_{2}$ catalyst and a negligible percentage on $\mathrm{ZnO}$ surface) and then exposed to UV light using a fluorescent tube (Philips TLD $15 \mathrm{~W}$, the maximum emission is at $365 \mathrm{~nm}$ ). The intensity at $365 \mathrm{~nm}$ measured by a radiometer (VLX-3W) was equal to 0,372 $\mathrm{mW} / \mathrm{cm}^{2}$. After each irradiation time, a $3 \mathrm{ml}$ of the solution was withdrawn and separate from $\mathrm{TiO}_{2}$ or $\mathrm{ZnO}$ particles by centrifugation (Sigma 1-1 Sk). The concentration of the clear solution was determined by UV-1800 SHIMADZU Spectrophotometer. The wavelength of the photodegradation was $654 \mathrm{~nm}$ (maximum wavelenght). Under solar light, the same approch as UV irradiation was followed. The intensity of the sunlight at $365 \mathrm{~nm}$ measured by a radiometer (VLX$3 \mathrm{~W}$ ) was equal to $2,72 \mathrm{mw} / \mathrm{cm}^{2}$. (1).

The photocatalytic degradation was calculated based on Eq.

$$
\% \text { Degradation efficiency }=\left[\frac{\mathrm{C}_{0}-\mathrm{C}_{\mathrm{t}}}{\mathrm{C}_{0}}\right] \times 100
$$

\section{RESULTS AND DISCUSSION}

\section{A. MB Photocatalytic Degradation in aqueous solution by $\mathrm{TiO} 2 / \mathrm{UV}$ and $\mathrm{ZnO} / \mathrm{UV}$}

The evolution of the concentration ratio $\mathrm{C} / \mathrm{C}_{0}$ of an aerated solution of $\mathrm{MB}(10 \mathrm{ppm})$ irradiated at $365 \mathrm{~nm}$ in the presence of $\mathrm{TiO}_{2}$ photocatalyst $(1 \mathrm{~g} / \mathrm{l})$, where $\mathrm{C}_{0}$ is the initial concentration, and $\mathrm{C}$ the concentration at $\mathrm{t}$ time, versus 
irradiation time $\mathrm{t}$ (Figure 1), shows clearly the disappearance of the pollutant. MB phototransformation was fast at the beginning of the reaction with an initial rate equal to 0,8 $\mu \mathrm{mol} . \mathrm{L}^{-1} \cdot \mathrm{min}^{-1}$. The pollutant was completely oxidized after 2 hours of irradiation and the half-life time was estimated at 22 minutes. The linear fit $\left(\mathrm{R}^{2}=0,999\right)$ arising from the variations $\ln \mathrm{C}_{0} / \mathrm{C}$ versus time (t) using only the experimental points corresponding to the first illumination minutes demonstrates that the disappearance followed a pseudo-first-order kinetic (insert of Figure 1). It is to note as well that the MB (10 ppm) direct photolysis at $365 \mathrm{~nm}$ was checked up to 2 hours and found negligible.

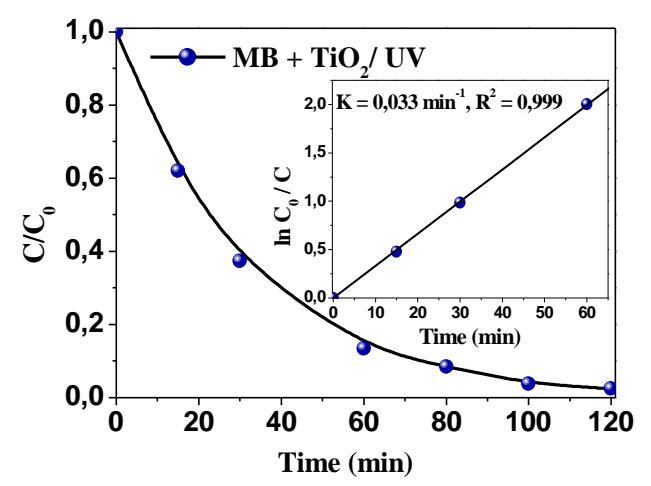

Fig. 1: Kinetics of MB (10 ppm) using $\mathrm{TiO}_{2}(1 \mathrm{~g} / \mathrm{l})$ nanoparticles under UV light.

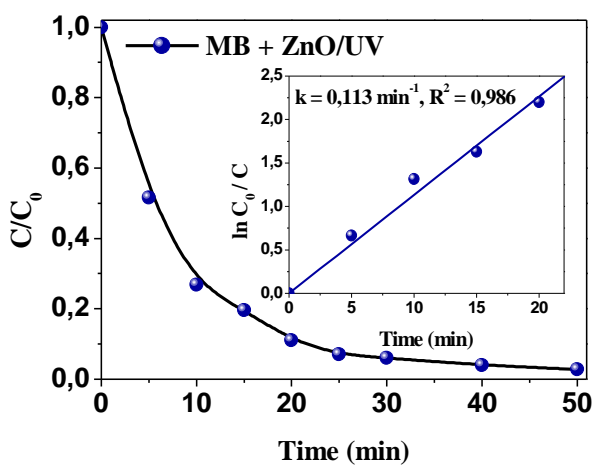

Fig. 2: Kinetics of the MB (10 ppm) photocatalytic degradation using $\mathrm{ZnO}$ (1 g/l) nanoparticles under UV light.

Keeping the same experimental conditions, the photocatalytic degradation of the pollutant $(10 \mathrm{ppm})$ at $365 \mathrm{~nm}$ in the presence of $\mathrm{ZnO}(1 \mathrm{~g} / \mathrm{l})$ catalyst was very efficient, the degradation was complete only after 50 minutes of irradiation time and the half-life time was 5,7 minutes (Figure 2). The variations $\ln \mathrm{C}_{0} / \mathrm{C}$ versus irradiation time (t) (Insert of Figure 2) were linear $\left(R^{2}=0,986\right)$, the photodegradation thus follows a pseudo-first-order kinetic. The apparent rate constant was equal to $0,113 \mathrm{~min}^{-1}$. The process $\mathrm{ZnO} / \mathrm{UV}$ is very effective regarding $\mathrm{MB}$ degradation.

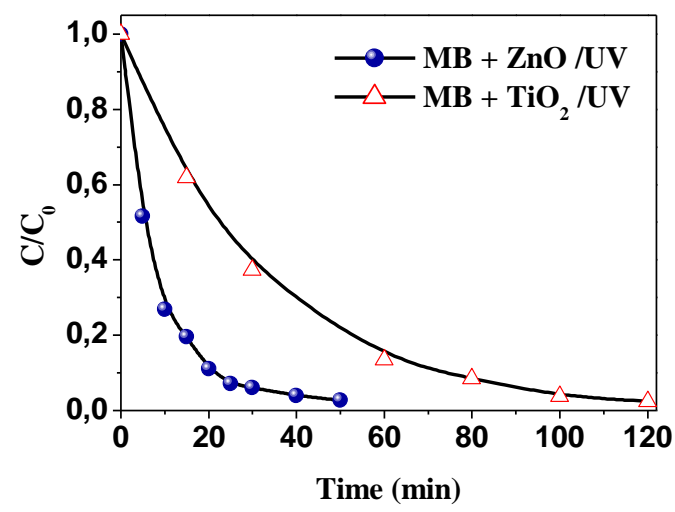

Fig. 3: Comparison between the photocatalytic degradation of $\mathrm{MB}$ (10 ppm) using $\mathrm{ZnO} / \mathrm{UV}$ and $\mathrm{TiO}_{2} / \mathrm{UV}$

It clearly appears from Figure 3 that $\mathrm{MB}$ disappearance was much faster in the presence of $\mathrm{ZnO}$ than $\mathrm{TiO}_{2}$. For both photocatalysts, the pollutant oxidation comes mainly from the attack of the hydroxyl radical, which is a very powerful oxidant. The total oxidation with $\mathrm{TiO}_{2}$ required 2 hours against only 50 minutes with $\mathrm{ZnO}$. The process $\mathrm{ZnO} / \mathrm{UV}$ was much more efficient than $\mathrm{TiO}_{2} / \mathrm{UV}$ process. This result can be attributed to the surface defect of $\mathrm{ZnO}$ photocatalyst over $\mathrm{TiO}_{2}$ enhancing its photocatalytic activity even it has a very lower effective surface area [11].

\section{B. Photocatalytic Degradation of MB in aqueous solution} by $\mathrm{TiO} 2 / \mathrm{SL}$ and $\mathrm{ZnO} / \mathrm{SL}$

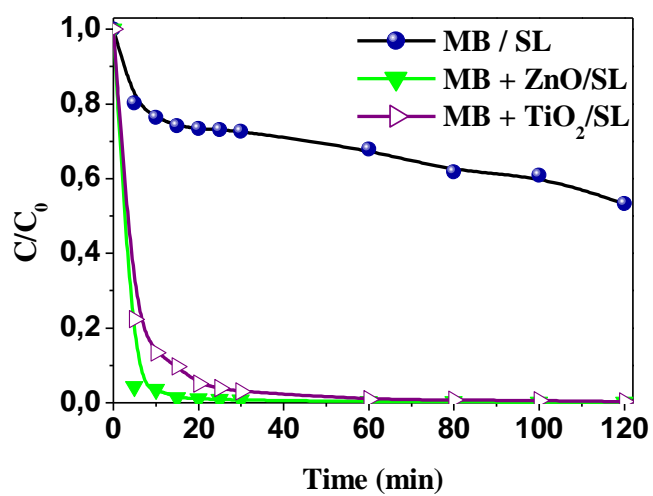

Fig. 4: Kinetics of the photocatalytic degradation of MB (10 ppm) using $\mathrm{TiO}_{2}$ and $\mathrm{ZnO}$ nanoparticles under Solar light

Solar radiation has the advantage of being an inexhaustible energy emitted by the sun, a free source without any toxic effects on our environment. In addition, the two photocatalysts absorb a small percentage of the total sunlight intensity. It would be interesting to investigate the photocatalytic degradation of an aerated $\mathrm{MB}$ solution in the presence of $\mathrm{TiO}_{2}$ $(1 \mathrm{~g} / \mathrm{l})$ and $\mathrm{ZnO}(1 \mathrm{~g} / \mathrm{l})$ under solar light (Figure 4). Experimentally, we followed the same experimental approach as UV irradiation; however, we exposed the MB solutions directly to the solar radiation (The sunlight intensity at $365 \mathrm{~nm}$ was equal to $2,72 \mathrm{~mW} / \mathrm{cm}^{2}$ ). $\mathrm{MB}$ direct photolysis under solar 
light seems to be non-negligible after 2 hours of SL irradiation. In accordance with the significant sunlight intensity absorbed by both photocatalysts, the disappearance kinetics were very fast. $\mathrm{ZnO}$ exhibited almost similar photocatalytic degradation as compared with $\mathrm{TiO}_{2}$.

C. Comparison between photocatalytic activities of $\mathrm{ZnO}$ and $\mathrm{TiO} 2$ under $U V$ and solar irradiation

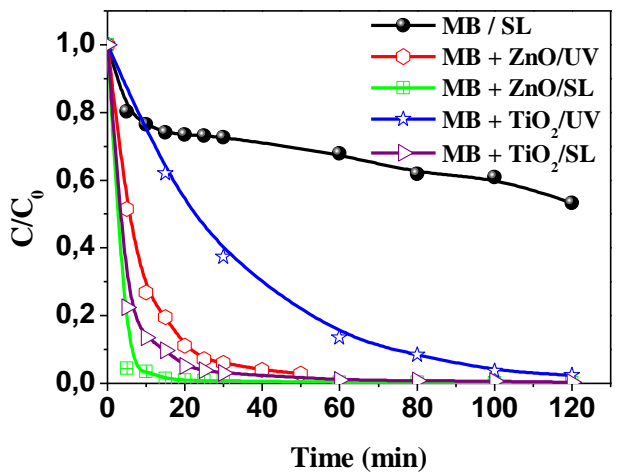

Fig. 5: Kinetics of the MB (10 ppm) photocatalytic degradation using $\mathrm{TiO}_{2}$ and $\mathrm{ZnO}$ nanoparticles under UV and Solar light irradiation.

To highlight the most effective process used, we plotted on the same graph all the MB phototransformation kinetics under UV and sunlight (Figure 5). From these curves, MB degradation efficiency was calculated after $10 \mathrm{~min}$ and $50 \mathrm{~min}$ of irradiation. These values were presented on Figure 6 allowing us to conclude the effectiveness order of the different processes used as follows:

$\mathrm{ZnO} / \mathrm{SL} \geq \mathrm{TiO}_{2} / \mathrm{SL}>\mathrm{ZnO} / \mathrm{UV}>\mathrm{TiO}_{2} / \mathrm{UV}$

Photocatalysis under solar radiation appears as the most effective process and both $\mathrm{ZnO}$ and $\mathrm{TiO}_{2}$ are promising photocatalysts for MB degradation.

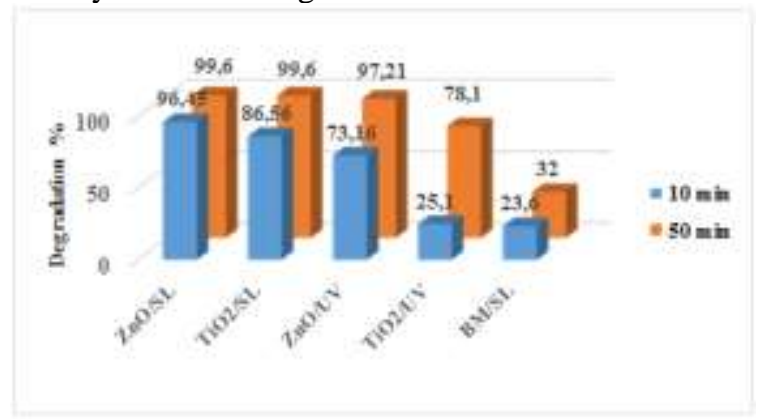

Fig. 6: Comparison between the different processes according to the irradiation time

\section{CONCLUSION}

In summary, the commercial $\mathrm{TiO}_{2}$ Degussa ( $\mathrm{P}$ 25) and $\mathrm{ZnO}$ nanoparticles can be the attractive candidates for photocatalytic textile wastewaters treatment. Under UV light, $\mathrm{ZnO}$ showed a better photocatalytic activity as compared with $\mathrm{TiO}_{2}$ even it has a larger effective surface area. Under the solar light, photocatalysis demonstrates to be economically and technically feasible, MB oxidation was found to be the most effective and $\mathrm{ZnO}$ exhibited almost similar photocatalytic efficiency as compared with $\mathrm{TiO}_{2}$.

\section{REFERENCES}

[1] M. Qamar, M. Muneer, "A comparative photocatalytic activity of titanium dioxide and zinc oxide by investigating the degradation of vanillin", Desalination, vol. 249, pp. 535-540, 2009. https://doi.org/10.1016/j.desal.2009.01.022

[2] M. S. Takriff, M. M. Ba-Abbad, A. A. H Kadhum, A. B. Mohamad and K. Sopian, "Solar photocatalytic degradation of 2,4-Dichlorophenol by $\mathrm{TiO}_{2}$ Nanoparticle prepared by sol-gel method", Advanced Materials Research, vol. 233-235, pp. 3032-3035, 2011. https://doi.org/10.4028/www.scientific.net/AMR.233-235.3032

[3] M. R. Hoffman, S. T. Martin, W. Choi and D. W. Bahnemannt, "Environmental applications of semiconductor photocatalysis", Chemical Reviews, vol. 95, pp. 69-96, 1995. https://doi.org/10.1021/cr00033a004

[4] Y. Ohko, K. I. Luchi, C. Niwa, T. Tatsuma, T. Nakashima, T. Iguchi, et al, "Beta-estradiol degradation by $\mathrm{TiO}_{2}$ photocatalysis as a means of reducing estrogenic activity", Environmental Science \& Technology, vol. 36 , pp. $4175-4181$ https://doi.org/10.1021/es011500a

[5] Y. Li, J. Niu, "Photocatalytic degradation kinetics and mechanism of pentachlorophenol based on superoxide radicals", Journal of Environmental Science, vol. 23, pp. 1911-1918, 2002. https://doi.org/10.1016/S1001-0742(10)60563-3

[6] S. S. Al-Shamali, "Photocatalytic degradation of methylene blue in the presence of $\mathrm{TiO}_{2}$ catalyst assisted solar radiation", Australian Journal of Basic and Applied Sciences, vol. 7, pp. 172-176, 2013 